10. Афанасьева Р.Ф., Чеботарёв А.Г., Константинов Е.И. Методические подходы к установлению класса условий труда по параметрам микроклимата на рабочих местах горнодобывающих предприятий // Горная промышленность. - 2013. - №. 6. - С. 72.

\title{
ГАЗОНОСНОСТЬ И ГАЗОДИНАМИЧЕСКИЕ ХАРАКТЕРИСТИКИ ГЛИНИСТО-КАРБОНАТНЫХ ПАЧЕК МЕЖДУ ІІ И III КАЛИЙНЫМИ ГОРИЗОНТАМИ СТАРОБИНСКОГО МЕСТОРОЖДЕНИЯ КАЛИЙНЫХ СОЛЕЙ
}

\author{
Н.А. Литвиновская ${ }^{1}$, А.П. Ключарев ${ }^{2}$ \\ 1. Горный институт УрО РАН, г. Пермь \\ 2. Пермский Национальный Исследовательский Политехнический Университет, г. Пермь
}

\begin{abstract}
Аннотация. В процессе проведения вскрывающих бремсбергов на шахтном поле Краснослободского рудника 2 РУ впервые проведены исследования газоносности и газодинамических характеристик глинисто-карбонатных пачек, залегающих между II и III калийными горизонтами. Первоначальные предположения о потенциальной опасности пород по газодинамическим явлениям не подтвердились. Полученные в ходе исследования показатели газоносности, начальной скорости газовыделения и давления свободного газа в массиве оказались близкими к фоновым значениям. Это говорит об отсутствии фактора газодинамической опасности из этих пород, а, следовательно, нет необходимости в специальных мероприятиях по предотвращению газодинамических явлений в процессе проведения выработок по этим породам.

Ключевые слова: газоносность пород, начальная скорость газовыделения, глинисто-карбонатные породы, Старобинское месторождение калийных солей, Краснослободской рудник.
\end{abstract}

\section{Введение}

Основными рабочими горизонтами на рудниках Старобинского месторождения являются II и III калийные горизонты. При строительстве Краснослободского рудника 2РУ ПАО «Беларуськалий» (рис. 1) было принято решение о вскрытии II калийного горизонта бремсбергами с III калийного горизонта $[1,2,3]$. Расстояние между горизонтами 150 м, и вскрывающие выработки проводились по соляным и глинисто-карбонатным пачкам. На момент проектирования и проведения бремсбергов никаких данных о содержании свободных газов в породах между горизонтами не было, так как такие исследования не проводились. Чтобы исключить риск газодинамических явлений при проведении выработок, были разработаны временные рекомендации. Кроме этого, так как никаких данных по газоносности и газодинамических характеристик пород не было, работы сопровождались обязательными научными исследованиями.

Целью исследования являлись газоносность, начальная скорость газовыделения и давления газа в массиве пород на всем протяжении выработок. Отдельное внимание уделялось глинисто-карбонатным пачкам. Породы этих пачек не устойчивые, трещиноватые, кроме того, в них часто встречаются доломито-известковые глинистые породы, доломитсодержащие слои, песчаники и алевролиты. Встречаются как слоистые, так и не слоистые породы. В каждой глинисто-карбонатной пачке породы пересечены трещинами, часто заполненными соляными породами. Все это при наличии газа в породах создает условия для формирования очагов газодинамических явлений, и глинисто-карбонатные породы, наряду с соляными породами III калийного горизонта, были признаны опасными по газодинамическим явлениям [4-8]. 


\section{Методика проведения исследований}

Исследование газоносности и газодинамических характеристик проводилось путем поинтервального бурения исследовательских скважин в кровлю выработок [9]. Каждый интервал герметизировался и делались замеры давления газа в массиве. Полученные данные использовались для расчета газоносности и начальной скорости газовыделения. Длина исследовательских скважин составляла 6-9 м. Интервалы герметизации были по 0,5 м, и в каждой скважине проводилось не менее 10 измерений. Таким образом получали данные о газонасыщенности пород, по которым планировалось дальнейшее проведение выработок. Всего по всем глинисто-карбонатным породам проведено более 100 замеров. Исследования охватили все глинисто-карбонатные пачки между II и III калийными горизонтами на всю их мощность.

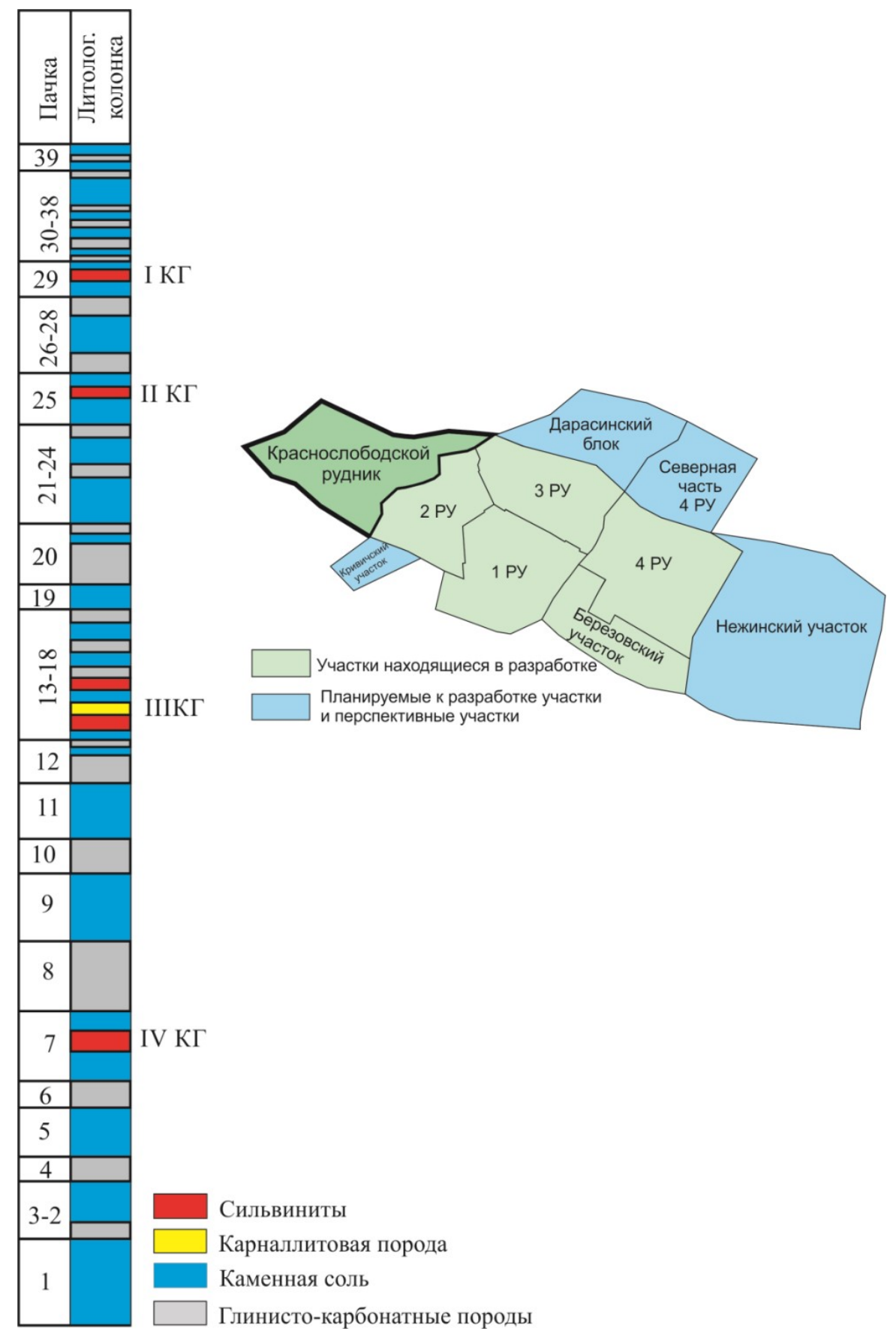

Рис. 1. Литологическая колонка пород и участки Старобинского месторождения калийных солей 


\section{Результаты исследований}

Исследования давления свободного газа, газоносности и начальной скорости газовыделения проводились минимум в двух исследовательских скважинах в каждой пачке. В зависимости от мощности исследуемой пачки количество скважин увеличивалось. Если невозможно было провести исследование пачки на всю мощность, то эксперимент повторялся до тех пор, пока не собирались данные по всей глинисто-карбонатной породе и не перебуривался контакт с соляной пачкой, залегающей выше.

В таблице представлены значения газоносности и начальной скорости газовыделения, полученные в результате шахтных исследований. Минимальные и максимальные значения, указанные в таблице, брались среди всех измерений, проведённых в породах соответствующей глинисто-карбонатной пачки, вне зависимости от того, сколько исследовательских скважин бурилось в данной пачке.

Результаты исследования газоносности и начальной скорости газовыделения

Таблица по глинисто-карбонатным пачкам

\begin{tabular}{|c|c|c|c|c|c|c|}
\hline \multirow{2}{*}{ Пачка } & \multicolumn{3}{|c|}{ Газоносность, $\mathrm{m}^{3} / \mathrm{M}^{3}$} & \multicolumn{3}{|c|}{$\begin{array}{c}\text { Начальная скорость газовыделе- } \\
\text { ния, л/мин }\end{array}$} \\
\hline & Мин. & Макс. & Средняя & Мин. & Макс. & Средняя \\
\hline 24 ГКП & 0,1 & 0,26 & 0,14 & 0,01 & 0,1 & 0,03 \\
\hline 22 ГКП & 0,05 & 0,15 & 0,08 & 0,01 & 0,13 & 0,05 \\
\hline 20 ГКП & 0,05 & 0,17 & 0,09 & 0,01 & 0,15 & 0,06 \\
\hline 18 ГКП & 0,1 & 0,018 & 0,11 & 0,01 & 0,35 & 0,07 \\
\hline 16 ГКП & 0,1 & 0,12 & 0,1 & 0,03 & 0,03 & 0,03 \\
\hline 14ГКП & 0,1 & 0,13 & 0,12 & 0,02 & 0,08 & 0,06 \\
\hline
\end{tabular}

На рисунке 2 представлены графики распределения газоносности и начальной скорости газовыделения по глинисто-карбонатным пачкам между II и III калийными горизонтами.

Из графиков видно, что наиболее газоносной является 24 глинисто-карбонатная пачка, однако значения начальной скорости газовыделения здесь не велики. Это говорит об отсутствии газодинамический опасности. Обратная ситуация наблюдается в породах 18 глинисто-карбонатной пачки. Здесь зафиксированы самые большие показания начальной скорости газовыделения, при этом значения газоносности не велики. Все это так же говорит об отсутствии фактора газодинамической опасности, тем более что средний показатель начальной скорости газовыделения скорее низкий и близок к фоновым значениям.

В целом значения газоносности и начальной скорости газовыделения свидетельствуют об отсутствии каких-либо существенных скоплений свободного газа. Это так же подтверждается результатами исследований давления свободного газа в массиве. Практически во всех исследовательских скважинах давление газа было равно 0,190 МПа, что является фоновым показателем. В 24 и 18 глинисто-карбонатных пачках, было зафиксировано максимальное давление, составляющее 0,191МПа. Такие колебания не являются значимыми. 

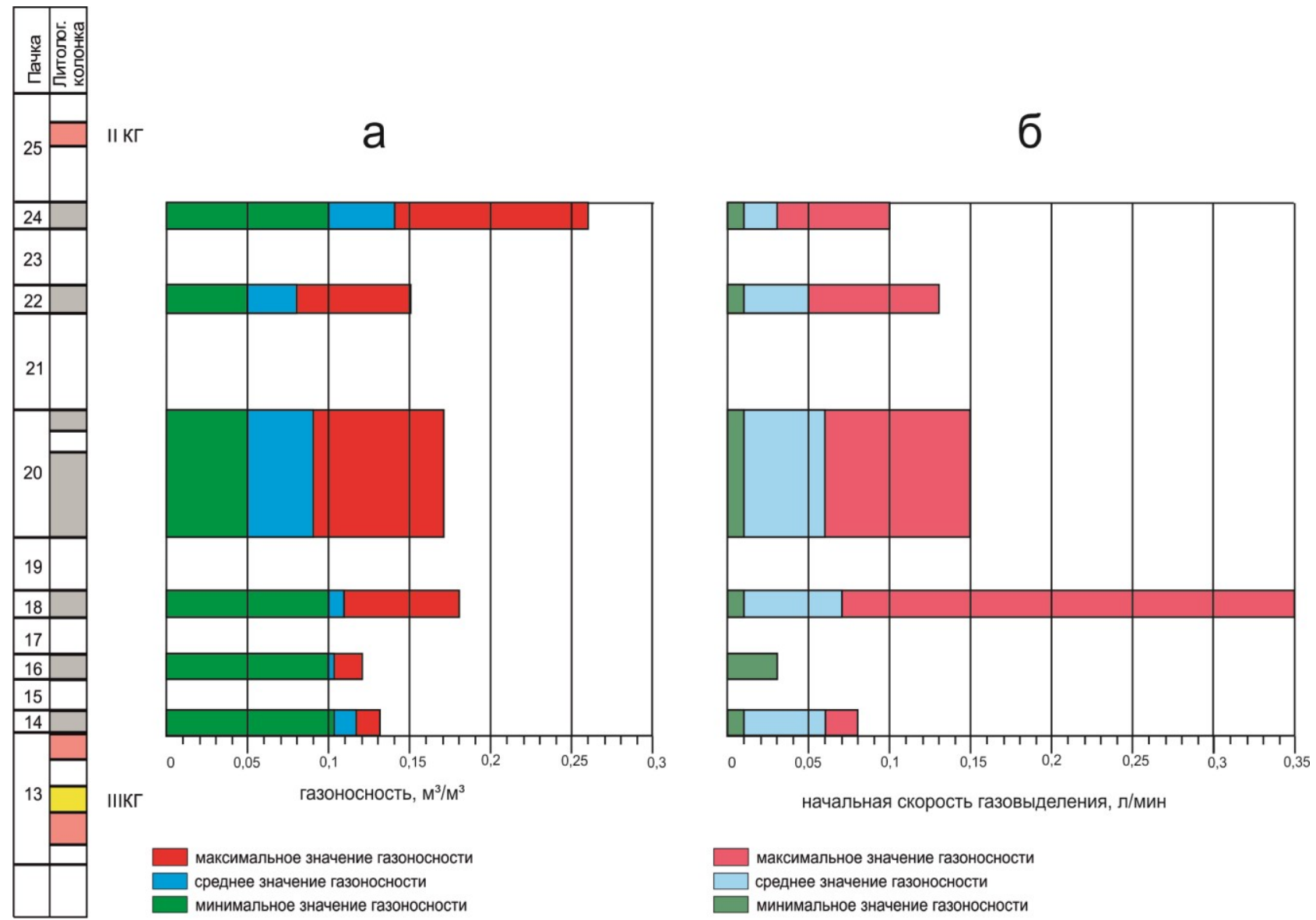

Рис. 2. Газоносность и начальная скорость газовыделения из пород 14-24 глинисто-карбонатных пачек Старобинского месторождения калийных солей

\section{Заключение}

По результатам проведенных исследований можно сделать вывод, что глинистокарбонатные породы между II и III калийными горизонтами не газоносны, не содержат скоплений свободного газа и не являются опасными по газодинамическим явлениям. Проведение горных выработок в данных породах возможно без специальных мер предотвращения ГДЯ.

\section{БИБЛИОГРАФИЧЕСКИЙ СПИСОК}

1. Исходные данные на проектирование 2 РУ. Развитие главных направлений горизонта - 450 м Краснослободского рудника. Разработать исходные данные для проекта вскрытия запасов западной площади шахтного поля Краснослободского рудника с пересечением Краснослободского разлома горными выработками: Отчет ОАО «БелГОРХИМПРОМ»; договор № 87-10, этап 10 / Рук. А.А. Крукович, Н.А. Зольников. - Минск, 2014. -218 с.

2. Барбиков Д.В., Андрейко С.С., Иванов О.В., Бобров Д.А. Оценка газодинамических характеристик горных пород Краснослободского разлома // Горн. журн. - 2018. - № 8. - С. 38-42. DOI: 10.17580/gzh.2018.08.04.

3. Андрейко С.С., Бобров Д.А., Нестеров Е.А., Лукьянец Е.В. Оценка газоносности и газодинамических характеристик пород соляных и глинисто-карбонатных пачек на шахтном поле рудника второго рудоуправления ОАО «Беларуськалий» // Недропользование. - 2020. - Т. 20, № 3. - С. 270-279. DOI:10.15593/2712-8008/2020.3.7.

4. Андрейко С.С., Калугин П.А., Щерба В.Я. Газодинамические явления в калийных рудниках: Генезис, прогноз и управление / под. ред. В.Я. Прушака. - Минск: Выш. шк., 2000. - 335 с.: ил.

5. Андрейко С.С. Механизм образования очагов газодинамических явлений в соляном породном массиве. - Пермь: Изд-во ПГТУ, 2008. - 196 с. 
6. Андрейко С.С., Лялина Т.А., Нестеров Е.А., Еловикова А.С. Оценка возможности развития газодинамических явлений при ведении горных работ на III калийном горизонте Краснослободского рудника 2 РУ // Горная механика и машиностроение. - 2012. - № 1. - С. 5-15.

7. Береснев С.П., Сенюк В.В., Гончар В.И., Андрейко С.С., Литвиновская Н.А. Исследование механизма формирования опасных по газодинамическим явлениям зон в породах калийного горизонта // Горн. журн. - 2010. - № 8. - С.31-33.

8. Андрейко С.С. Современное состояние проблемы газодинамических явлений на действующих и вводимых в эксплуатацию калийных рудниках // Горное эхо. - 2019. - № 2 (75). - С. 82-89. - DOI: 10.7242/echo.2019.2.20.

9. Земсков А.Н., Кондрашев П.И., Травникова Л.Г. Природные газы калийных месторождений и меры борьбы с ними. - Пермь: Тип. Купца Тарасова, 2008. - 412 с.: ил., табл.

\title{
ЧИСЛЕННОЕ МОДЕЛИРОВАНИЕ ВОЗДУХОРАСПРЕДЕЛЕНИЯ НА ПЕРИОД ПРОХОДКИ МЕЖСТВОЛОВОЙ СБОЙКИ В УСЛОВИЯХ ОДНОГО ИЗ РУДНИКОВ БЕЛОРУССИИ
}

\author{
С.В. Мальцев \\ Горный институт УрО РАН, г. Пермь
}

\begin{abstract}
Аннотация: При проходке межстволовой сбойки особенно важным является вопрос обеспечения рабочих зон комбайновых комплексов требуемыми расходами воздуха. В настоящей работе разработаны технические решения при проходке межстволовой сбойки и по организации движения свежего и исходящего потоков воздуха в одном стволе. Для обеспечения комбайновых комплексов требуемым количеством воздуха при проветривании используются вентиляторные установки ARP-800. При выполнении расчетов учтены нормативные утечки через вентиляционный трубопровод. В настоящей работе определено направление естественной тяги и ее влияние на проветривание рудника. Путем численного моделирования определена минимально возможная по техническим характеристикам производительность вентилятора главного проветривания.
\end{abstract}

Ключевые слова: численное моделирование, воздухораспределение, межстволовая сбойка, клетьевой ствол, скиповой ствол.

\section{Введение}

Проектной документацией на отработку рассматриваемого рудника предусматривается всасывающий способ и центральная схема проветривания рудника. Шахтное поле вскрыто двумя вертикальными стволами диаметром 8 м каждый. Ствол № 1 (скиповой) оборудован скипами и предназначен для подъема отбитой сильвинитовой руды на поверхность, а также для подачи свежего воздуха (глубина 850 метров). Ствол № 2 (клетьевой) оборудован клетями и предназначен для спуска-подъема людей, материалов и оборудования, а также для выдачи исходящей струи воздуха (глубина 836 метров).

В данной работе представлены варианты численных расчетов двух задач:

1) обеспечение трех рабочих зон комбайновых комплексов, задействованных на проходке межстволовой сбойки, требуемым количеством воздуха;

2) выбор схемы проветривания в начальный период ведения работ после соединения стволов в условиях рудника.

Для обогрева воздуха в холодное время года на рассматриваемые периоды предполагается к использованию два теплообменника ВЕНЭ-500-473-03-02-01 (мощность каждого - 188 кВт, возможный обогрев воздуха $-15 \mathrm{~m}^{3} /$ с одним теплообменником). 